\title{
Effect of gradual substitution of soyabean meal by Nigella sativa meal on growth performance, carcass traits and blood lipid profile of growing Japanese quail
}

\author{
M.E. Abd El-Hack ${ }^{1,6}$, M. Alagawany ${ }^{1}$, M. Saeed ${ }^{2,3}$, M. Arif ${ }^{4}$, M.A. Arain ${ }^{4,5}$, \\ Z.A. Bhutto ${ }^{4,5}$ and S.A. Fazlani ${ }^{4,5}$ \\ ${ }^{1}$ Zagazig University, Department of Poultry, Faculty of Agriculture, Zagazig, 44511, Egypt \\ ${ }^{2}$ University of Agriculture, Institute of Animal Sciences, Faisalabad 38040, Pakistan \\ ${ }^{3}$ Northwest A\&F University, College of Animal Sciences, Yangling 712100, China \\ ${ }^{4}$ University of Sargodha, Department of Animal Sciences, College of Agriculture, Sargodha 40100, Pakistan \\ ${ }^{5}$ Lasbela University of Agriculture, Water and Marine Sciences, Faculty of Veterinary and Animal Sciences \\ Uthal, Balochistan 3800, Pakistan
}

KEY WORDS: Japanese quail, Nigella sativa meal, performance, carcass, blood, lipids

Received: 11 January 2016

Revised: $\quad 17$ May 2016

Accepted: 26 August 2016

${ }^{6}$ Corresponding author:

e-mail:m.ezzat@zu.edu.eg
ABSTRACT. The aim of the study was to evaluate the effect of different inclusion levels of Nigella sativa meal (NSM) on growth performance, carcass yield and blood lipid profile of 300 unsexed one-week old Japanese quails. The experimental diets contained four levels of NSM replacing 0 (control), 20, 30 and $40 \%$ of soyabean meal (SBM) in growing Japanese quail diets. Live body weight was linearly $(P=0.017)$ and quadratically $(P=0.024)$ increased at week 3 of age and only quadratically $(P>0.001)$ at week 6 of age due to $30 \%$ SBM substitution. Birds fed diets with 20 and 30\% SBM replaced by NSM consumed more feed in comparison with other animals during 3-6 and 1-6 week of age. The substitution of $20 \%$ SBM for the same percent of NSM resulted in a significant $(P<0.001)$ linear increase in both dressing and carcass percentages in comparison with the control and other treatment groups, giblets yield was also significantly (linearly $P=0.011$ and quadratically $P=0.021$ ) affected. A gradual reduction in serum total lipids, total cholesterol and $\mathrm{HDL}$-cholesterol was observed along with the increasing level of NSM in the diet, except HDL which was elevated when $40 \%$ of SBM was replaced. It could be concluded that NSM could partially replace SBM up to $30 \%$ in growing Japanese quail diets without any harmful hazards regarding performance, feed utilization and carcass traits. Moreover, the blood lipid parameters are decreased with increasing NSM content in the diet.

\section{Introduction}

It is well known that prices of maize and soyabean, which are mainly used in poultry diet, have reached the highest values in years. Thus, there is an urgent need for the alternative protein sources which would be affordable and nutritious. The soyabean meal (SBM) is the most commonly used protein source in poultry feeding which is known for its high quality. Due to the fact that SBM is the major by-product of oil extraction from soyabeans, costs and availability of SBM are strongly correlated with 
the price of agricultural commodities on the world market (Laudadio and Tufarelli, 2011). The prices are influenced by variations in economic growth, changes in consumer product preferences and weather conditions (Jezierny et al., 2010). Therefore, the price and availability of SBM on the global market may change rapidly; thereby increasing interest in maximizing the use of locally produced feed ingredients including grain legumes (Laudadio et al., 2011). The best reducing costs strategy is the development of diet formulation based on alternative, locally available ingredients, so the nutritionists proposed many alternatives for poultry diets such as raw faba bean or sunflower meal (Abd El-Hack and Alagawany, 2015; Alagawany et al., 2015).

Medicinal plants and their extracts are presently gaining the great importance in livestock production as well as health care systems because of their broad beneficial effects - promoting growth and production, immune enhancement and safeguarding health (Alagawany et al., 2016). The recent studies have described various biological and protective impacts of black cumin (Nigella sativa), including antioxidant, anti-inflammatory, anticancer, antibacterial, immunomodulatory and health-promoting activities (Abd El-Hack et al., 2016).

$N$. sativa meal (NSM) contains most essential amino acids together with about $33 \%$ of crude protein (El-Nattat and El-Kady, 2007). Furthermore, NSM production is expected to increase in the near future due to its extended use as a medical seed (Zeweil, 1996). Zeweil (1996) also reported that NSM could be successfully included as a protein replacer (up to $13.5 \%$ ) in the growing Japanese quail diets. However, too high levels of NSM depressed growth and feed utilization of these animals. Therefore, this study aimed to examine the effects of the inclusion of NSM as a substitute for soyabean meal in growing Japanese quail diets on growth performance, carcass yield and some blood metabolites.

\section{Material and methods}

\section{Experimental design and husbandry}

The study was conducted at Poultry Research Farm, Poultry Department, Faculty of Agriculture, Zagazig University, Zagazig (Egypt). All procedures were reviewed by the Local Experimental Animal Care Committee, and approved by the institutional ethics committee of Poultry Department, Faculty of Agriculture, Zagazig University, Zagazig (Egypt) in December 2014.
Table 1. Composition and chemical analysis of experimental diets

\begin{tabular}{|c|c|c|c|c|}
\hline \multirow{2}{*}{ Indices } & \multicolumn{4}{|c|}{ SBM $\%$ replaced by NSM ${ }^{1}, \%$} \\
\hline & 0 & 20 & 30 & 40 \\
\hline \multicolumn{5}{|l|}{ Ingredients, $\%$} \\
\hline maize & 52.01 & 50.40 & 49.51 & 48.45 \\
\hline SBM $44 \%$ & 40.00 & 32.00 & 28.00 & 24.00 \\
\hline maize gluten meal & 2.50 & 4.30 & 5.20 & 6.30 \\
\hline NSM & 0.00 & 8.00 & 12.00 & 16.00 \\
\hline Di-calcium phosphate & 1.67 & 1.37 & 1.24 & 1.10 \\
\hline limestone & 0.81 & 1.01 & 1.10 & 1.19 \\
\hline vitamin-mineral premix ${ }^{2}$ & 0.30 & 0.30 & 0.30 & 0.30 \\
\hline $\mathrm{NaCl}$ & 0.30 & 0.30 & 0.30 & 0.30 \\
\hline DL-methionine & 0.12 & 0.06 & 0.04 & 0.00 \\
\hline L-lysine & 0.37 & 0.27 & 0.21 & 0.16 \\
\hline soyabean oil & 1.92 & 1.99 & 2.10 & 2.20 \\
\hline \multicolumn{5}{|l|}{ Calculated analysis, $\%^{3}$} \\
\hline crude protein & 24.08 & 24.04 & 24.00 & 24.08 \\
\hline crude fibre & 3.98 & 4.28 & 4.43 & 4.58 \\
\hline $\mathrm{Ca}$ & 0.85 & 0.85 & 0.85 & 0.85 \\
\hline P (available) & 0.45 & 0.45 & 0.45 & 0.45 \\
\hline lysine & 1.61 & 1.61 & 1.61 & 1.61 \\
\hline methionine + cysteine & 0.88 & 0.88 & 0.88 & 0.88 \\
\hline $\mathrm{ME}^{4}, \mathrm{kcal} \cdot \mathrm{kg}^{-1}$ diet & 2906 & 2900 & 2900 & 2900 \\
\hline
\end{tabular}

${ }^{1} \mathrm{SBM}$ - soyabean meal, NSM - Nigella sativa meal; ${ }^{2}$ each $2.5 \mathrm{~kg}$ consists of: IU: vit $A 12000000$, vit $D_{3} 2000000$; g: vit. E 10, vit. $K_{3} 2$, vit. $B_{2} 49$, vit. $B_{6} 105$, pantothenic acid 10 , niacin 20 , biotin 50 , Fe 30 , Mn 40, Cu 3, Zn 45; mg: vit. B 1000 , vit. $B_{12} 10$, folic acid 1000 , choline chloride 500 , Co 200 , Si $100{ }^{3}$ calculated according to NRC (1994); ${ }^{4} \mathrm{ME}$ - metabolizable energy

A total of 300 unsexed one-week old Japanese quails were randomly assigned into 4 treatment groups, of 75 chickens each. Each group was sub-divided into 5 replicates, of 15 chickens each. Each replicate was housed in a cage $(90 \times 40 \times 40 \mathrm{~cm})$. Four experimental isonitrogenous and isocaloric diets were formulated: a basal diet and three diets with graded substitution levels $(0,20,30$ and $40 \%)$ of soyabean meal (SBM) with $N$. sativa meal (NSM), which represent 8,12 and $16 \%$ NSM addition to the diet (Table 1).

Chickens were grown in brooders with raised wire floors and were reared under the same conditions with $23 \mathrm{hlight}: 1 \mathrm{~h}$ dark. Feed and water were available ad libitum throughout the whole experimental period (1-6 weeks of age). All chickens received feeds in mash form until 42 day of age, according to their treatment.

\section{Growth performance}

Chickens were weighed individually at one week intervals to obtain live body weight (LBW). Average daily feed intake (FI), body weight gain (BWG) and feed efficiency (FE) were calculated at the end of each period (after week 1, 3, 6) and 
during each period (1-3, 3-6, 1-6). Feed waste was recorded daily and on this basis the feed consumption was calculated. Protein efficiency ratio (PER) was calculated from BWG divided by protein intake (Kamran et al., 2008). Also, energy utilization (EU) was calculated as follows: $\mathrm{EU}=$ metabolizable energy (ME) consumed (kcal) during the studied period/ BWG (g) during the same period.

\section{Carcass characteristics}

At the end of the experiment, 20 birds (five from each group) were randomly chosen, weighed and manually slaughtered at 6 week of age. The carcasses were weighed and the weights of the liver, gizzard and heart were recorded and expressed as $\mathrm{g} \cdot \mathrm{kg}^{-1}$ of slaughter weight (SW). Carcass and dressed weights were studied (dressed $\%=$ (carcass weight + giblets weight) / live body weight).

\section{Blood sampling and laboratory analyses}

Six birds per treatment were randomly used to collect blood samples after slaughtering into sterilized tubes. Samples were left to coagulate and centrifuged at $3500 \mathrm{rpm}$ for $15 \mathrm{~min}$ to obtain serum. The serum samples were kept at $-20{ }^{\circ} \mathrm{C}$ until further analyses. The following serum biochemical parameters: $\mathrm{mmol} \cdot \mathrm{l}^{-1}$ : total lipids, total cholesterol, high density lipoprotein (HDL) cholesterol, low density lipoprotein (LDL) cholesterol levels were measured using a Shimadzu 1200 spectrophotometer (Shimadzu Scientific Instruments; Kyoto, Japan), and kits and calibrators from Biodiagnostic Co. (Giza, Egypt), according to Akiba et al. (1982).

\section{Statistical analysis}

Data were subjected to ANOVA procedure using a completely randomized design using the GLM procedure of SAS (version 9.2, 2008). The differences among means were determined using the post-hoc Tukey's test. The statements of statistical significance are based on $P<0.05$ unless otherwise stated.

\section{Results and discussion}

\section{Growth performance and feed utilization}

There was observed a significant effect of SBM substitution for NSM levels on both LBW and BWG at all experimental periods (Table 2). It was noticeable that LBW was linearly $(P=0.017)$ and quadratically $(P=0.024)$ increased at week 3 of age and only quadratically $(P<0.001)$ at week 6 of age due o SBM substitution levels up to $30 \%$. The results obtained for BWG had the same trend. The heaviest
Table 2. Effect of dietary Nigella sativa meal (NSM) replacing soyabean meal (SBM) on growth performance of Japanese quail from 1 to 6 week of age

\begin{tabular}{|c|c|c|c|c|c|c|}
\hline \multirow{2}{*}{ Indices } & \multicolumn{4}{|c|}{ SBM \% substituted by NSM, \% } & \multirow{2}{*}{ SEM $^{1}$} & \multirow{2}{*}{$\frac{P \text {-value }}{\text { linear quadratic }}$} \\
\hline & 0 & 20 & 30 & 40 & & \\
\hline \multicolumn{7}{|c|}{ Live body weight, $g$} \\
\hline week 1 & 19.99 & 19.98 & 19.91 & 20.16 & 0.03 & 0.2040 .053 \\
\hline week 3 & $87.74^{a}$ & $87.97^{\mathrm{a}}$ & $87.16^{\mathrm{a}}$ & $75.74^{b}$ & b 1.86 & 0.0170 .024 \\
\hline week 6 & $222.28^{c}$ & $249.87^{\mathrm{a}}$ & $241.16^{b}$ & $211.49^{d}$ & 4.63 & $0.079<0.001$ \\
\hline \multicolumn{7}{|c|}{ Body gain, $g$} \\
\hline week 1-3 & $34.84^{\mathrm{a}}$ & $4.86^{\mathrm{a}}$ & $4.80^{\mathrm{a}}$ & 3.96 & 0.13 & $0.016 \quad 0.022$ \\
\hline week 3-6 & $6.40^{\mathrm{b}}$ & $7.71^{\mathrm{a}}$ & $7.33^{\mathrm{a}}$ & 6.46 & 0.18 & $0.339<0.001$ \\
\hline week 1-6 & $5.77^{c}$ & $6.56^{\mathrm{a}}$ & $6.32^{b}$ & 5.46 & 0.12 & $0.008<0.001$ \\
\hline
\end{tabular}

${ }^{1}$ SEM - standard error means; ${ }^{2}$ linear and quadratic effect of NSM meal; ${ }^{\text {a-d }}$ - means with different superscripts within a row are significantly different

birds were observed in the experimental group fed diet with 20\% SBM substituted for NSM in different phases studied. Our results are in line with those reported by Zeweil (1996) who observed that LBW and BWG of growing Japanese quails fed diet including 9 or $18 \%$ NSM instead of SBM protein (6.78 or $13.54 \%$ in the diet) were significantly $(P<0.01)$ higher in comparison with control group. Tekeli (2014) postulated that feeding Japanese quail chickens diets with 4 or $8 \%$ NSM resulted in the best LBW in comparison with the control. Jamroz and Kamel (2002) found a stimulating impact of black cumin seed on the digestive system, which reflects positively in increased absorption and growth performance. The supplementation of $N$. sativa in the diet increases the bile flow rate which consequently increases emulsification simulating the pancreatic lipase activity (helps in the fat digestion and fat-soluble vitamins absorption) as theorized by Crossland (1980). The improved body weight could be also due to antimicrobial activity of the black cumin seed active components (Gilani et al., 2004). Also the same authors found that N. sativa has many components such as thymohydroquinone and thymoquinone which possess antimicrobial properties and are known for their pharmacological impacts. Furthermore, black cumin seed acts as antifungal and antibacterial agent and so exhibits protective action vs hepatotoxicity; all these actions can result in improved nutrient utilization (Rathee et al., 1982). It has been reported that $N$. sativa can directly or indirectly activate thyroid gland through the pituitary gland. Thyroid hormones are essential for the metabolism because they increase the rate of metabolism which can lead to improved amino acid utilization (by fastening their metabolism) (More et al., 1980).

In our study both LBW and BWG were negatively influenced when the substitution level of 
Table 3. Effect of dietary Nigella sativa meal (NSM) replacing soyabean meal (SBM) on feed intake and feed efficiency of Japanese quail from 1 to 6 week of age

\begin{tabular}{|c|c|c|c|c|c|c|c|}
\hline \multirow{2}{*}{ Indices } & \multicolumn{4}{|c|}{ SBM $\%$ replaced by NSM, $\%$} & \multirow{2}{*}{ SEM $^{1}$} & \multicolumn{2}{|l|}{$P$-value ${ }^{2}$} \\
\hline & 0 & 20 & 30 & 40 & & linear & quadratic \\
\hline \multicolumn{8}{|c|}{ Feed intake, $g$} \\
\hline week 1-3 & $13.78^{\mathrm{a}}$ & $13.30^{\mathrm{a}}$ & $12.86^{\mathrm{a}}$ & $10.86^{b}$ & 0.35 & $<0.001$ & 0.008 \\
\hline week 3-6 & $22.33^{b}$ & $26.89^{a}$ & $25.80^{\mathrm{a}}$ & $21.00^{b}$ & 0.75 & 0.501 & $<0.001$ \\
\hline week 1-6 & $18.06^{b}$ & $20.09^{a}$ & $19.33^{\mathrm{a}}$ & $15.93^{c}$ & 0.49 & 0.011 & $<0.001$ \\
\hline \multicolumn{8}{|c|}{ Feed efficiency, g gain $\cdot \mathrm{g}^{-1}$ feed } \\
\hline week 1-3 & 0.350 & 0.366 & 0.376 & 0.366 & 0.007 & 0.405 & 0.582 \\
\hline week 3-6 & 0.283 & 0.286 & 0.283 & 0.310 & 0.005 & 0.128 & 0.196 \\
\hline week 1-6 & 0.313 & 0.313 & 0.316 & 0.326 & 0.003 & 0.128 & 0.362 \\
\hline
\end{tabular}

SBM reached $40 \%$ (corresponding to $16 \%$ of NSM). The declined LBW and BWG in birds fed diets supplemented with $16 \%$ NSM instead of $40 \%$ SBM could be due to the high content of crude fibre in NSM and consequently deterioration of digestibility and depressed appetite of birds as reported by Azeem et al. (2014). Zeweil (1996) observed that body weight was declined with increased substitution of SBM protein with NSM protein at 28 or $38 \%$ ( 20.32 or $27.58 \%$ in the diet, respectively).

There was observed the linear and quadratic $(P<0.05)$ increase in feed consumption within weeks $1-3$ and 1-6 in groups fed diets with replacement level of SBM for NSM up to $30 \%$ (Table 3). At the middle phase (weeks 3-6 of age), feed intake quadratically $(P<0.001)$ varied due to the NSM levels in the diet. Birds fed diets with 20 or $30 \%$ SBM replaced by NSM ( 8 and $12 \%$ of NSM, respectively) consumed more feed in comparison with the control and 40\% SBM substituted group. Conversely, the worst palatability and consequently the lowest feed consumption were observed in the $40 \%$ replacement group. This reduction in feed intake may be due to the high content of fibre in NSM which increased as the level of NSM in the diet increased (Table 1). The improved feed intake due to NSM up to $12 \%$ (30\% SBM substituted by NSM) may be caused by improved quails' appetite as cited by Abdel-Hady et al. (2009) and Tekeli (2014). In this respect, Gilani et al. (2004) and Amad and Radman (2013) suggested that $N$. sativa as feed supplement acts as stimulator for the digestive system activity and promotes the appetite and palatability. Similar results were obtained by Al-Homidan et al. (2002) who reported improved feed intake by incorporating black cumin seeds in broiler rations. Moreover, Azeem et al. (2014) demonstrated a significant increase in feed
Table 4. Effect of dietary Nigella sativa meal (NSM) replacing soyabean meal (SBM) on energy and protein efficiency of Japanese quail from 1 to 6 week of age

\begin{tabular}{|c|c|c|c|c|c|c|}
\hline \multirow{2}{*}{ Indices } & \multicolumn{4}{|c|}{ SBM \% replaced by NSM, \% } & \multirow{2}{*}{$\mathrm{SEM}^{1}$} & \multirow{2}{*}{$\frac{P \text {-value }}{\text { linear quadratic }}$} \\
\hline & 0 & 20 & 30 & 40 & & \\
\hline \multicolumn{7}{|c|}{ Energy utilization, ME intake/BWG ${ }^{3}$} \\
\hline week 1-3 & 8.27 & 7.96 & 7.78 & 8.02 & 0.18 & 0.5640 .614 \\
\hline week 3-6 & 10.13 & 10.13 & 10.21 & 9.44 & 0.14 & 0.1720 .150 \\
\hline week 1-6 & 9.32 & 9.28 & 9.25 & 8.86 & 0.09 & 0.1510 .275 \\
\hline \multicolumn{7}{|c|}{ Protein efficiency, g gain per protein intake } \\
\hline week 1-3 & 1.46 & 1.52 & 1.55 & 1.52 & 0.03 & 0.4680 .687 \\
\hline week 3-6 & 1.19 & 1.19 & 1.18 & 1.28 & 0.01 & 0.1720 .161 \\
\hline week 1-6 & 1.29 & 1.30 & 1.31 & 1.36 & 0.01 & 0.1750 .329 \\
\hline
\end{tabular}

consumption in broilers fed NSM up to $10 \%$ which could be due to the different ways of affecting body metabolism by NSM. The contradictive results were reported by Sogut et al. (2012) who postulated that $7 \%$ addition of ground black cumin seeds to the broiler diets caused a significant decrease $(P<0.01)$ in feed consumption as compared with the control group.

No linear or quadratic differences $(P<0.05)$ were noticed in feed efficiency, energy utilization or protein efficiency due to SBM substitution for NSM (Table 3 and 4). In line with our results, Amad and Radman (2013) claimed that feed conversion ratio was not significantly affected by $N$. sativa seeds addition to the broiler diet. Further, Saeid et al. (2013) observed that rations containing black cumin seeds at various levels had no statistical impact on feed efficiency during all experimental periods. In contrast, several researchers, such as Abdel-Hady et al. (2009), confirmed that $N$. sativa seed had a significant influence on feed conversion ratio, energy utilization and protein efficiency. Obtained results showed good concentration of protein, fat, fibre, $\mathrm{N}$-free extractives, vitamins, variety of minerals and moisture content on the basis of dry matter analysis in $N$. sativa seed (Ali and Blunden, 2003). Also, based on dry matter content analysis the components levels were: $\mathrm{g} \cdot \mathrm{kg}^{-1}$ : crude protein $216, \mathrm{~N}$-free extractives 249 , fat 406 , crude fibre $84 ; \mathrm{mg} \cdot \mathrm{kg}^{-1}$ : iron 105 , copper 18 , zinc 60 , phosphorus 527, calcium 1860 , thiamine 15.4 , niacin 57 , pyridoxine $5.0 ; \mu \mathrm{g} \cdot \mathrm{kg}^{-1}$ : folic acid 160 as reported and documented by Ali and Blunden (2003) and Sultan et al. (2009).

\section{Carcass characteristics}

The substitution of $20 \%$ SBM for $8 \%$ of NSM resulted in a significant $(P<0.001)$ linear increase in both dressing and carcass percentages in com- 
parison with the control and other treatment groups. Giblets yield was also significantly $(P=0.11$ and $P=0.21$ for linear and quadratic analysis, respectively) affected as a result of the substitution levels. A significant increases in liver percentage $(P=0.002$ and $P<0.001$ for linear and quadratic analysis, respectively), heart $(P<0.001$ for both linear and quadratic analysis) and gizzard (quadratic; $P<0.001$ ) were also associated with replacing $20 \%$ SBM by $8 \%$ of NSM in growing Japanese quail diet. This increase in the dressing, carcass and edible organs percentages indicate that $N$. sativa may have a good impact on the protein metabolism (Azeem et al., 2014). Our results are in accordance with those reported by Zeweil (1996) who demonstrated that the inclusion of NSM in quail diets positively influenced carcass percentage, heart, gizzard and spleen weights. Moreover, Toghyani et al. (2010) observed an increase in carcass, breast, thigh, wing, liver, neck and abdominal fat weights in broilers fed diet containing $1 \%$ black cumin seeds. Otherwise, AL-Beitawi et al. (2009) observed no improvement in carcass traits by adding crushed as well as uncrushed $N$. sativa seeds into broiler diets. In addition, Amad and Radman (2013) reported no significant impact on the slaughter weight, the dressing percentage and edible inner organs weight due to addition of $N$. sativa oil seeds into diets.

Table 5. Effects of dietary Nigella sativa meal (NSM) replacing soyabean meal (SBM) on carcass traits of Japanese quail at 6 week of age

\begin{tabular}{|c|c|c|c|c|c|c|c|}
\hline \multirow{2}{*}{ Indices, \% } & \multicolumn{4}{|c|}{ SBM \% replaced by NSM, \% } & \multicolumn{3}{|c|}{ SFM1 $P$-value ${ }^{2}$} \\
\hline & 0 & 20 & 30 & 40 & & linear & quadratic \\
\hline Dressing & $62.48^{\text {bc }}$ & $65.26^{a}$ & $63.33^{b}$ & $61.78^{c}$ & 0.41 & 0.172 & $<0.001$ \\
\hline Carcass & $57.48^{c}$ & $60.44^{a}$ & $58.94^{b}$ & $56.96^{c}$ & 0.43 & 0.613 & $<0.001$ \\
\hline Giblets & $5.00^{\mathrm{a}}$ & $4.81^{\mathrm{a}}$ & $4.39^{b}$ & $4.82^{\mathrm{a}}$ & 0.25 & 0.011 & 0.021 \\
\hline Liver & $10.18^{c}$ & $12.71^{\mathrm{a}}$ & $10.81^{b}$ & $9.04^{d}$ & 0.40 & 0.002 & $<0.001$ \\
\hline Gizzard & $9.91^{\mathrm{b}}$ & $12.84^{\mathrm{a}}$ & $12.62^{\mathrm{a}}$ & $8.86^{b}$ & 0.54 & 0.686 & $<0.001$ \\
\hline Heart & $5.57^{\mathrm{b}}$ & $6.66^{a}$ & $4.29^{c}$ & $4.35^{c}$ & 0.30 & $<0.001$ & 0.001 \\
\hline
\end{tabular}

1,2 - see Table 2; ${ }^{a-d}$ - means with different superscripts within a row are significantly different

\section{Blood lipid profile}

The blood lipid parameters are vital signs of the physiological and nutritional ccndition of animals (Alagawany and Abd El-Hack, 2015). All studied lipid profile components were significantly (linear; $P<0.05)$ affected by substitution levels of SBM with NSM (Table 6). A gradual reduction in serum total lipids, total cholesterol and HDL-cholesterol content was observed along with an increasing level of NSM in the diet, except the HDL-cholesterol level (elevated in group with $40 \% \mathrm{SBM}$ replaced by NSM). In the
Table 6. Effect of dietary Nigella sativa meal (NSM) replacing soyabean meal (SBM) on lipid profile of Japanese quail at 6 week of age

\begin{tabular}{|c|c|c|c|c|c|c|c|}
\hline \multirow{2}{*}{$\begin{array}{l}\text { Lipid profile, } \\
\mathrm{mmol} \cdot \mathrm{I}^{-1}\end{array}$} & \multicolumn{4}{|c|}{ SBM \% replaced by NSM, \% } & \multicolumn{3}{|c|}{ SFM $^{1} \frac{P \text {-value }}{2}$} \\
\hline & 0 & 20 & 30 & 40 & & linear & quadratic \\
\hline Total lipids & $27.06^{\mathrm{a}}$ & $28.08^{a}$ & $21.34^{b}$ & $20.24^{b}$ & 0.88 & $<0.001$ & 10.444 \\
\hline Total cholesterol & $5.79^{a}$ & $5.51^{\mathrm{a}}$ & $5.07^{b}$ & $4.73^{c}$ & 0.13 & $<0.001$ & 10.103 \\
\hline HDL cholesterol & $2.43^{a}$ & $2.28^{b}$ & $2.13^{b}$ & $2.23^{b}$ & 0.03 & 0.003 & 0.120 \\
\hline LDL cholesterol & $0.675^{\mathrm{ab}}$ & $0.585^{b}$ & $50.724^{a b}$ & b $0.809^{a}$ & 0.02 & 0.022 & 20.010 \\
\hline
\end{tabular}

1,2 - see Table 2; abc - means with different superscripts within a row are significantly different

same time, LDL-cholesterol level was the lowest in the group fed diet with 20\% SBM substituted for NSM, while the highest value was observed in the $40 \%$ SBM substituted group. The decrease in serum total lipids and total cholesterol content could be attributed to the high content of unsaturated fatty acids by feeding on diets containing $N$. sativa seeds which may stimulate the cholesterol oxidation to bile acids as explained by Tollba and Hassan (2003). Another reason for the decrease in serum lipids is the 'Nigellone' - active substance present in NSM which is mainly responsible for 3-hydroxy-3-methyl-CoA reductase (HMG-CoA) activity reduction. Furthermore, in several cases, a reduction in secretion of some hormones from the cortex of the adrenal glands, like glucocorticoids and androgens, could be the reason for the observed serum cholesterol decrease. Reducing the secretion of these hormones causes a run-down in fatty acids secretion from the adipose tissue which leads to a depression in fatty acids and cholesterol blood levels as well (Laudadio et al., 2015). Similarly to our results, Abdel-Hady et al. (2009) suggested that feeding growing Japanese quails diets with NSM addition significantly decreased total lipids and cholesterol concentration in serum in comparison with the control group. Similarly Amad and Radman (2013) showed that the inclusion of $N$. sativa seeds in broilers diet decreased serum cholesterol level comparing with the control group. Also, Ali et al. (2014) confirmed the ability of $N$. sativa seeds in combination with vitamin $\mathrm{C}$ to reduce blood content of total cholesterol in broiler chickens. Contrarily, Toghyani et al. (2010) observed that blood triglyceride, cholesterol and LDL levels were not statistically altered by the addition of $N$. sativa seeds to broiler diets.

\section{Conclusions}

Partial replacement of soyabean meal (SBM) by Nigella sativa meal (NSM) up to 20 and $30 \%$ (8 and $12 \%$ NSM addition, respectively) improves growth performance of growing Japanese quails, increases 
carcass and giblets yield and decreases blood total lipids and cholesterol levels. Therefore, NSM as an alternative feedstuff can partially replace SBM up to $30 \%$ in growing Japanese quail diets without any harmful effect on performance, feed utilization, carcass traits as well as blood lipid parameters.

\section{References}

Abd El-Hack M.E., Alagawany M., 2015. Performance, egg quality, blood profile, immune function, and antioxidant enzyme activities in laying hens fed diets with thyme powder. J. Anim. Feed Sci. 24, 127-133

Abd El-Hack M.E., Alagawany M., Farag M.R., Tiwari R., Karthik K., Dhama K., 2016. Nutritional, healthical and therapeutic efficacy of black cumin (Nigella sativa) in animals, poultry and humans. Int. J. Pharmacol. 12, 232-248

Abdel-Hady A.A., Abdel-Azeem F.A., Abdel-Rafea A.A., Gamal A.G., 2009. Effect of replacement of soybean meal protein by Nigella sativa meal protein on performance of growing Japanese quail. Egypt. Poultry Sci. J. 29, 407-422

Akiba Y., Jensen L.S., Barb C.R., Kraeling R.R., 1982. Plasma estradiol, thyroid hormones, and liver lipid content in laying hens fed different isocaloric diets. J. Nutr. 112, 299-308

Alagawany M., Abd El-Hack M.E., 2015. The effect of rosemary herb as a dietary supplement on performance, egg quality, serum biochemical parameters, and oxidative status in laying hens. J. Anim. Feed Sci. 24, 341-347

Alagawany M., Ashour E.A., Reda F.M., 2016. Effect of dietary supplementation of garlic (Allium sativum) and turmeric (Curcuma longa) on growth performance, carcass traits, blood profile and oxidative status in growing rabbits. Ann. Anim. Sci. 16, 489-505

Alagawany M., Farag M.R., Abd El-Hack M.E., Dhama K., 2015. The practical application of sunflower meal in poultry nutrition. Adv. Anim. Vet. Sci. 3, 634-648

AL-Beitawi N.A., EL-Ghousein S.S., Nofal A.H., 2009. Replacing bacitracin methylene disalicylate by crushed Nigella sativa seeds in broiler rations and its effects on growth, blood constituents and immunity. Livest. Sci. 125, 304-307

Al-Homidan A., Al-Qarawi A.A., Al-Waily S.A., Adam S.E.I., 2002. Response of broiler chicks to dietary Rhazya stricta and Nigella sativa. Brit. Poultry Sci. 43, 291-296

Ali B.H., Blunden G., 2003. Pharmacological and toxicological properties of Nigella sativa. Phytother. Res. 17, 299-305

Ali O.A.A., Suthama N., Mahfud L.D., 2014. The effect of feeding black cumin (Nigella Sativa) and vitamin C on blood lipid profiles and growth performance of broilers. Int. Refereed J. Eng. Sci. 3, 28-33

Amad A.A., Radman M.A., 2013. Effects of dietary black cumin seeds (Nigella sativa) on performance, carcass traits and some blood parameters in broiler chickens. In: Proceedings of Conference on International Research on Food Security, Natural Resource Management and Rural Development. Tropentag, Stuttgart (Germany)

Azeem T., Zaib-Ur-Rehman, Umar S., Asif M., Arif M., Rahman A., 2014. Effect of Nigella sativa on poultry health and production: a review. Sci. Lett. 2, 76-82

Crossland J., 1980. Lewis's Pharmacology. $5^{\text {th }}$ Edition. Churchill Livingston. London (UK), pp. 656-657
El-Nattat W.S., El-Kady R.I., 2007. Effect of different medicinal plant seeds residues on the nutritional and reproductive performance of adult male rabbits. Int. J. Agri. Biol. 9, 479-485

Gilani A.H., Jabeen Q., Khan M.A.U., 2004. A Review of medicinal uses and pharmacological activities of Nigella sativa. Pak. J. Biol. Sci. 7, 441-451

Jamroz D., Kamel C., 2002. Plant extracts enhance broiler performance. In non-ruminant nutrition: antimicrobial agents and plant extracts on immunity, health and performance. J. Anim. Sci. 80, Suppl. 1, E41

Jezierny D., Mosenthin R., Bauer E., 2010. The use of grain legumes as a protein source in pig nutrition: a review. Anim. Feed Sci. Tech. 157, 111-128

Kamran Z., Sarwar M., Nisa M., Nadeem M.A., Mahmood S., Babars M.E., Ahmed S., 2008. Effect of low-protein diets having constant energy-to-protein ratio on performance and carcass characteristics of broiler chickens from one to thirty-five days of age. Poultry Sci. 87, 468-474

Laudadio V., Ceci E., Lastella N.M.B., Tufarelli V., 2015. Dietary highpolyphenols extra-virgin olive oil is effective in reducing cholesterol content in eggs. Lipids Health Dis. 14, 5 doi:10.1186/ s12944-015-0001-x

Laudadio V., Ceci E., Tufarelli V., 2011. Productive traits and meat fatty acid profile of broiler chickens fed diets containing micronized fava beans (Vicia faba L. var. minor) as the main protein source. J. Appl. Poultry Res. 20, 12-20

Laudadio V., Tufarelli V., 2011. Dehulled-micronised lupin (Lupinus albus L. cv. Multitalia) as the main protein source for broilers: influence on growth performance, carcass traits and meat fatty acid composition. J. Sci. Food Agric. 91, 2081-2087

More T., Rai A.K., Singh M., 1980. Note on the effect of thermal exposure on body fluid composition of different breeds and crosses of sheep. Indian J. Anim. Sci. 50, 207-209

NRC, 1994. Nutrient Requirements of Poultry. $9^{\text {th }}$ revised Edition. National Academy Press. Washington, DC (USA)

Rathee P.S., Mishra S.H., Kaushal R., 1982. Antimicrobial activity of essential oil, fixed oil and unsaponifiable matter of Nigella sativa linn. Indian J. Pharm. Sci. 44, 8-10

Saeid J.M., Arkan M.B., AL-Baddy M.A., 2013. Effect of adding garlic powder (Allium sativum) and black seed (Nigella sativa) in feed on broiler growth performance and intestinal wall structure. J. Nat. Sci. Res. 3, 35-41

Sogut H., Inci H., Ozdemir G., 2012. Effect of supplemented black seed (Nigella sativa) on growth performance and carcass characteristics of broilers. J. Anim. Vet. Adv. 11, 2480-2484

Sultan M.T., Butt M.S., Anjum F.M., Jamil A., Akhtar S., Nasir M., 2009. Nutritional profile of indigenous cultivar of black cumin seeds and antioxidant potential of its fixed and essential oil. Pak. J. Bot. 41, 1321-1330

Tekeli A., 2014. Nutritional value of black cumin (Nigella sativa) meal as an alternative protein source in poultry nutrition. J. Anim. Sci. Adv. 4, 797-806

Toghyani M., Toghyani M., Gheisari A., Ghalamkari G., Mohammadrezaei M., 2010. Growth performance, serum biochemistry and blood hematology of broiler chicks fed different levels of black seed (Nigella sativa) and peppermint (Mentha piperita). Livest. Sci. 129, 173-178

Tollba A.A.H., Hassan M.S.H., 2003. Using some natural additives to improve physiological and productive performance of broiler chicks under high temperature conditions. 2- Black cumin (Nigella sativa) or garlic (Allium sativum). Egypt. Poultry Sci. 23, 327-340

Zeweil H.S., 1996. Evaluation of substituting Nigella sativa oil meal for soybean meal on the performance of growing and laying Japanese quails. Egypt. Poultry Sci. 16, 451-477 